\title{
KONSEP KETELADANAN GURU DAN IMPLEMENTASINYA DALAM PERSPEKTIF PENDIDIKAN ISLAM
}

\author{
Mohammad Saat Ibnu Waqfin \\ Universitas KH. A. Wahab Hasbulllah Jombang \\ Fakultas Agama Islam \\ ibnusaat@unwaha.ac.id
}

\begin{abstract}
Abstrak
One of the most important and influential educational components is the teacher. Because the teacher is a central figure in improving the quality of education in students. Teachers in carrying out their duties are required to carry out various conditions, duties and responsibilities as instructors, educators and trainers. With a variety of demands that are so big and heavy, teachers in reality sometimes pay little attention to and implement these demands, so that they will influence and reduce the quality of education, especially students.

The concept of teacher exemplary in terms of Islamic education is very important and is a very influential method in the process of formation and development of students. And this has been applied by the Apostle to his friends.

As an educator, the teacher who becomes a character, role model and identification for students and their environment the teacher must implement the quality of his personality which includes authority, responsibility, independence, discipline, code of ethics, compassion, and mingling with society in daily life both in school environment and outside the school environment.

Thus, the example of the teacher implemented in daily life will lead to the achievement of the goal of Islamic education to the fullest.

From the explanation above, this is where the importance of this theme is about the example of the teacher in the perspective of scientific education to be studied by the author in the study of literature as a consideration or reference for educators, especially teachers.
\end{abstract}

Keywords: Teacher Exemplary, Implementation, Islamic Education

\begin{abstract}
Abstrak
Salah satu komponen pendidikan yang paling penting dan berpengaruh adalah guru. Karena guru merupakan figur sentral dalam meningkatkan mutu pendidikan pada anak didik. Guru dalam menjalankan tugasnya dituntut untuk melaksanakan berbagai syarat, tugas dan tanggung jawab sebagai pengajar, pendidik dan pelatih. Dengan berbagai tuntutan yang begitu besar dan berat, guru dalam realitasnya terkadang kurang memperhatikan dan melaksanakan tuntutan tersebut, sehingga akan mempengarui dan mengurangi kualitas pendidikan, terutama anak didik.

Konsep keteladanan guru ditinjau dari pendidikan Islam adalah sangat penting dan merupakan metode yang sangat influentif dalam proses pembentukan dan perkembangan anak didik. Dan hal ini telah diterapkan oleh rasulullah kepada sahabat - sahabatnya.

Sebagai seorang pendidik, guru yang menjadi tokoh, panutan dan identifikasi bagi peserta didik dan lingkungannya guru harus mengimplementasikan kualitas kepribadiannya yang
\end{abstract}


mencakup wibawa, tanggung jawab, mandiri, disiplin, kode etik, kasih sayang, dan berbaur dengan masyarakat dalam kehidupan sehari - hari baik di lingkungan sekolah maupun di luar lingkungan sekolah. Dengan demikian, maka keteladanan guru yang diimplementasikan dalam kehidupan sehari - hari akan mengantarkan pada tercapainya tujuan pendidikan Islam secara maksimal.

Dari penjelasan di atas, maka disinilah pentingnya tema ini yaitu tentang keteladanan guru dalam perspektif pendidikan ilmiah untuk dikaji oleh penulis dalam kajian kepustakaan sebagai bahan pertimbangan atau rujukan para pendidik khususnya guru.

Kata Kunci : Keteladanan Guru, Implementasi, Pendidikan Islam

\section{A. Pendahuluan}

Sebagai suatu sistem, pendidikan memiliki sejumlah komponen yang saling berkaitan antar satu dengan yang lainnya untuk mencapai tujuan yang ditetapkan. Komponen tersebut antara lain komponen kurikulum Guru, metode, sarana prasarana, dan evaluasi. Selanjutnya, dari kesekian komponen pendidikan tersebut, guru merupakan komponen terpenting, terutama dalam mengatasi berbagai permasalahan yang berkaitan dengan peningkatan mutu pendidikan. Dalam kaitan ini Muchtar Buchori mengatakan bahwa, yang akan dapat memperbaiki situasi Pendidikan pada akhirnya berpulang pada Guru yang sehari-hari bekerja di lapangan; mulai dari Guru TK sampai Guru Besar. Mulai tindakan mereka dari hari ke hari , dari bulan ke bulan, dari tahun ke tahun Guru benar-benar menentukan nasib pendidikan. Kalau tindakan mereka dari hari ke hari bertambah baik, maka akan menjadi lebih baik pulalah keadaan dunia pendidikan.

Sehingga guru dapat disamakan dengan pasukan tempur yang menentukan kemenangan atau kekalahan dalam berperang. ${ }^{63}$

Ilmu datang dari Tuhan, guru pertama adalah Tuhan. Pandangan yang menembus langit ini tidak boleh tidak telah melahirkan sikap pada orang Islam

${ }^{63}$ Abudin Nata, Paradigma Pendidikan Islam, (Jakarta: PT. Grasindo, 2001), 132. 


\section{KONSEP KETELADANAN GURU DAN IMPLEMENTASINYA DALAM}

PERSPEKTIF PENDIDIKAN ISLAM

bahwa ilmu tidak terpisah dari guru, maka kedudukan guru amat tinggi dalam Islam. Al-Ghozali dalam Ihya' Ulummuddin, sebagai mana dikutip al-Abrasyi mengatakan: "Seseorang yang berilmu yang kemudian bekerja dengan ilmunya itu dialah yang bekerja di bidang pendidikan sesungguhnya ia telah memilih pekerjaan yang terhormat dan sangat penting, maka hendaknya ia memelihara adab dan sopan santun dalam tugasnya".64

Gambararan tentang hakikat pendidik dalam Islam, adalah orang-orang yang bertanggung jawab terhadap perkembangan peserta didik dengan mengupayakan seluruh potensi anak didik baik affektif, kognitif dan psikomotor. Senada dengan ini Moh F adhil al- Djamali menyebutkan, bahwa pendidik adalah orang yang mengarahkan manusia kepada kehidupan yang baik sehingga terangkat derajat kemanusiaannya sesuai dengan kemampuan dasar yang di miliki manusia. Marimba mengartikan pendidik sebagai orang yang memikul pertanggung jawaban sebagai pendidik, yaitu manusia dewasa yang karena hak dan kewajibanya bertanggung jawab tentang pendidikan peserta didik.

Dalam menjalani tugas keguruannya seorang guru harus menjadi sosok yang dapat menghadirkan sejumlah jawaban ketika disodorkan berbagai permasalahan. Ketika anak didik tidak tahu, maka guru tampil sebagai penunjuk dan pengarah. Ketika anak didik loyo dalam belajar, maka guru tampil sebagai dinamo yang memberikan dorongan hasrat belajar. Ketika anak didik diracuni narkoba guru selayaknya jadi penawar dengan prilaku yang menyejukkan dan bersikap arif. Ketika anak didik membutuhkan figur yang "ideal", maka sosok guru tampil ke

${ }^{64}$ Ahmad Tafsir, Ilmu Pendidikan dalam Perspektif Islam, Cet. VII, (Bandung: Remaja Rosda Karya, 2007), 78 . 
depan sebagai personifikasi nilai-nilai ideal. ${ }^{65}$ Itulah sosok guru yang mendapatkan penghargaan dan harapan sedemikian tinggi yang kemudian melahirkan ungkapan "Guru, Ratu, Wong Tuo Akaro" taatilah pertama-tama gurumu, lalu rajamu, baru kemudian orang tuamu. ${ }^{66}$

Dalam konteks sosial budaya jawa kata guru sering dikonotasikan kepanjangan dari kata "Digugu dan di tiru" tidaklah berlebihan bila anak didik selalu mengharapkan figur guru yang senantiasa memperhatikan kepentingan mereka. figur guru yang selalu memperhatikan kepentingan anak didik biasanya mendapatkan ekstra perhatian dari anak didik. ${ }^{67}$

\section{B. Keteladanan Guru}

Kata keteladanan berasal dari kata teladan yang artinya sesuatu atau perbuatan yang patut untuk ditiru. Jadi keteladanan menurut definisi ini adalah segala tingkah laku yang baik serta pantas untuk ditiru dan diikuti. ${ }^{68}$

Sedangkan dalam Islam, keteladanan telah tergambar jelas dalam pribadi Rasulullah SAW yang telah berhasil merombak masyarakat jahiliyah menuju masyarakat Islamiyah yang dipenuhi keluhuran moral.

Pada dasarnya menusia cenderung membutuhkan sosok teladan dan anutan yang mampu mengarahkan manusia pada jalan kebenaran sekaligus menjadi perumpamaan dinamis yang menjelaskan cara mengamalkan syariat Allah. Oleh

\footnotetext{
${ }^{65}$ Muhammad Nurdin, Pendidikan yang Menyebalkan, (Jogyakarta: Arruz Media, 2005), 32. ${ }^{66}$ Muchtar Buchori, Spektrum Problematika Pendidikan di Indonesia, (Jogyakarta: PT. Tiara Wacana, 1994), 107.

${ }^{67}$ Syaiful Bahri Djamarah, Guru dan Anak Didik dalam Interaksi Edukatif, (Jakarta: PT. Rineka Cipta, 2002), 70 .

${ }^{68}$ Mulyasa, Menjadi Guru Profesional, (Bandung: Remaja Rosda Karya, 2006), 37.
} 


\section{KONSEP KETELADANAN GURU DAN IMPLEMENTASINYA DALAM PERSPEKTIF PENDIDIKAN ISLAM}

karena guru sebagai orang yang banyak melakukan interaksi dengan murid hendaknya mampu menjadi panutan bagi anak didiknya. ${ }^{69}$

Keteladanan dalam pendidikan Islam adalah metode influentif yang paling meyakinkan keberhasilannya dalam mempersiapkan dan membentuk anak didik dalam ilmu pengetahuan, moral, spiritual dan sosial. Hal ini karena pendidik adalah contoh terbaik dalam pandangan anak yang akan ditirunya dalam tidak tanduknya, tata santunnya, disadari atau tidak, bahkan tercetak dala jiwa dan perasaan suatu gambarn pendidik tersebut, diketahui atau tidak diketahui. ${ }^{70}$

Maka uraian tersebut di atas jelaslah bahwa figur keteladanan dalam dunia pendidikan sangat penting dan sangat di butuhkan. Apa lagi pada zaman sekarang ini yang penuh tantangan dan harapan di mana figur keteladanan semakin tipis bahkan hampir hilang. Masyarakat hampir kehilangan panutan. Sementara masyarakat membutuhkan panutan yang akan di jadikan pijakan dalam menapaki kehidupan, lebih-lebih bagi anak didik yang belum mampu membuat keputusan sendiri, keteladanan bagi mereka sangat di butuhkan agar mereka tidak tersesat dalam memilih idola atau panutan.

Status guru mempunyai implikasi terhadap peran dan fungsi yang menjadi tanggung jawabnya. Guru memiliki satu kesatuan peran dan fungsi yang tidak terpisahkan, antara kemampuan mendidik, mengajar dan melatih. Ketiga kemampuan tersebut merupakan kemampuan integratif, antara yang satu dengan yang lain tidak dapat dipisahkan. Seseorang yang dapat mendidik, tetapi tidak memiliki kemampuan mengajar dan melatih tidaklah dapat disebut sebagai guru

\footnotetext{
69 Ramayulis, Ilmu Pendidikan Islam, (Jakarta: Kalam Mulia, 2006), 174.

70 Abdullah Nasih Ulwan, Pedoman Pendidikan Anak dalam Islam,, (Semarang: Asy-Syifa, 1993), 2.
} 
yang paripurna. Ketiga kemampuan tersebut, secara terminologis akademis dapat dibedakan antara satu dengan yang lain. Namun, dalam kenyataan praktik di lapangan keempatnya harus menjadi stu kesatuan utuh yang tidak dapat dipisahpisahkan.

Dari sisi lain, guru sering dicitrakan memiliki peran ganda yang di kenal sebagai EMASLIMDEF (educator, manager, administrator, supervisor, leader, inivator, motivator, dinamisator, evaluator, dan facilitator) EMASLIM lebih merupakan peran kepala seskolah. Akan tetapi, dalam skala mikro di kelas, peran itu juga harus dimiliki oleh guru.

Educator merupakan peran yang utama dan yang terutama, khususnya untuk peserta didik pada jenjang pendidikan dasar. Peran ini lebih tampak sebagai teladan bagi peserta didik, sebagai role model, memberikan contoh dalam hal sikap dan, prilaku dan membentuk kepribadian peserta didik.

Manager pendidik memiliki peran intuk menegakan ketentuan dan tata tertib yang telah disepakati bersama di sekolah, memberikan arahan atau rambu-rambu ketentuan agar tata tertib di sekolah dapat dilaksanakan dengan sebaik-baiknya oleh seluruh warga sekolah.

Administrator guru memiliki peran untuk melaklsanakan administrasi sekolah, seperti mengisi buku presensi siswa, buku daftar nilai, buku rapor, administrasi kurikulum, administrasi nilai dan lain sebagainya. Bahkan yang paling penting adalah menyampaian rapor atau laporan pendidikan kepada orang tua siswa dan masyarakat. 


\section{KONSEP KETELADANAN GURU DAN IMPLEMENTASINYA DALAM}

PERSPEKTIF PENDIDIKAN ISLAM

Supervisor terkait dengan pemberian bimbingna dan pengawasan kepada pesesrta didik, memahami permasalahan yang dihadapi peserta didik, menumukan permasalahan yang terkait dengan proses pembelajaran, dan akhirnya memberikan jalan keluar pemecahan masalahnya.

Leader bagi guru lebih tepat di bandingkan dengan peran sebagai manajer. Karena manajer bersifat kaku terhadap ketentuan yang ada. Dari aspek penegakan disiplin misalnya, guru lebih menekankan disiplin mati. Sementara itu, sebagai leader guru lebih memberikan kebebasan secara bertanggung jawab terhadap peserta didik. Dengan demikian, disiplin yang ditegakkan oleh guru dari peran sebagai leader ini adalah disiplin hidup.

Inovatator seorang guru harus memiliki kemampuan belajar yang cukup tinggi untuk menambah pengetahuan dan keterampilannya sebagai guru. Tanpa adanya semangat belajar yang tingi, mustahil guru dapat menghasilkan inovasiinovasi yang bermanfaat untuk meningkatkan mutu pembelajaran di sekolah.

Motivator untuk meningkatkan semangat dan gairah belajar yang tinggi, siswa perlu memiliki motivasi yang tinggi, baik motivasi dari dalam diri sendiri (intrinsik) maupun dari luar (ekstrinsik), yang utamanya berasal dari gurunya sendiri.

Dinamisator untuk memberikan dorongan kepada siswa dengan cara menciptakan suasana lingkungan pembelajaran yang kondusif. ${ }^{71}$

Evaluator guru di tuntut untuk menjadi evaluator yang baik dan jujur denag memberikan penilaian yang menyentuh aspek intrinsik dan ekstrinsik. Penilaian terhadap aspek intrinsik lebih menyentuh pada aspek kepribadian anak didik, yakni aspek nilai, (values) Berdasarkan hal ini, guru harus bisa memberikan penilaian ${ }^{71}$ Suparlan, Guru sebagai Profesi, (Bandung: Remaja Rosda Karya, 2005), 29. 
dalam dimensi yang luas. Penilaian terhadap kepribadian anak didik tentu lebih di utamakan dari pada penilaian terhadap jawaban anak didik ketika diberi tes. Anak didik yang berprestasi baik belum tentu memiliki kepribadian yang baik. Jadi penilaian itu pada hakikatnya di arahkan pada perubahan kepribadian anak didik agar menjadi manusia susila yang cakap. ${ }^{72}$

Fasilitator guru dalam hal ini akan memberikan fasilitas atau kemudahan dalam proses belajar-mengajar. Misalnya saja dengan menciptakan suasana kegiatan belajar yang sedemikian rupa serasi dengan perkembangan siswa sehingga interaksi belajar mengajar berlangsung secara efektif. Hal ini bergayaut dengan semboyan "TUT WURI HANDAYANI"73

\section{Pendidikan Islam}

Pendidikan secara umum berasal dari istilah peadagogiek yang sering disebut dengan paedgogos (Yunani) yang berasal dari kata peados (anak) dan agoge (saya membimbing dan memimpin) Pada zaman Yunani Kuno paedagogos berarti seorang pelayan (bujang) yang pekerjaannya mengantar dan menjemput anak-anak dari sekolah. Kemudian pengertian ini berubah menjadi pekerjaan yang mulia, karena pengertian paedagog (paedagogos) berarti seseorang yang tugasnya membimbing anak di dalam pertumbuhannya ke rah berdiri sendiri dan bertanggung jawab. ${ }^{74}$

Secara sederhana dan umum makna pendidikan adalah sebagai usaha manusia untuk menumbuhkan dan mengembangkan potensi-potensi pembawaan

\footnotetext{
72 Saiful Bahri Djamarah, Guru dan Anak dalam Interaksi Edukatif, (Jakarta: Rineka Cipta, 2000), 48.

73 Sadirman, Interkasi dan Motivasi Belajar Mengajar, (Jakarta: Raja Gravindo Persada, 2007), 146.

74 Djumaransyah Indar, Filsafat Pendidikan, (Surabaya: Karya Adimata, 1994), 16.
} 
baik jasmani maupun rohani sesuai dengan nilai yang ada pada suatu masyarakat dan kebudayaan. ${ }^{75}$

Dalam UU tentang Sistem Pendidikan Nasional, Pendidikan diartikan sebagai "usaha sadar dan terencana untuk mewujudkan suasana belajar dan proses pembelajaran agar peserta didik secara aktif mengembangkan potensi-potensi dirinya untuk memiliki kekuatan spiritual keagamaan, pengendalian dirinya, masyarakat, bangsa dan negara. ${ }^{76}$ Dengan demikian, maka pendidikan pada hakekatnya adalah proses bimbingan, pembelajaran atau pelatihan terhadap anak, generasi muda, agar nantinya bisa berkehidupan dan bisa melaksanakan peran dan tugas hidupnya dengan sebaik-baiknya.

\section{Metodologi Penelitian}

Dalam penulisan ini penulis memuat data-data yang akan diteliti dengan menggunakan metode kualitatif yaitu suatu penelitian yang akan menghasilkan data deskriptif berupa kata-kata tertulis atau lisan dari orang-orang dan perilaku yang dapat diamati. ${ }^{77}$ Dalam penelitian kualitatif ini juga, penulis memuat data-data yang diteliti melalui metode library research. Metode library research yaitu pendekatan karya ilmiah dengan kajian kepustakaan, atau dengan menggunakan buku-buku yang berkaitan dengan permasalahan yang akan diangkat oleh penulis. ${ }^{78}$ Adapun penulis menggunakan metode pendekatan psikologis. M. Arifin menjelaskan bahwa yang dimaksud dengan pendekatan psikologis yaitu pendekatan yang

\footnotetext{
${ }^{75}$ Fuad Ihsan, Dasar-dasar Kependidikan, (Jakarta: Rineka Cipta, 1996), 1 - 2.

${ }^{76}$ Tim Pustaka Merah Putih, Undang-Undang Sistem Pendidikan nasional Guru dan Dosen, (Yogyakarta: Pustaka Merah Putih, 2007), 7.

${ }^{77}$ Lexsy J. Moleong, Metodologi Penelitian Kualitatif, Cet IV, (Bandung: PT. Remaja Rosda Karya, 2007), 4.

${ }^{78}$ Sutrisno Hadi, MA, Methodologi Research, Jilid I (Yogyakarta: Andi Offset, 2004), 4.
} 
berpandangan bahwa manusia adalah makhluk Tuhan yang berada dalam proses perkembangan dan pertumbuhan rohaniah dan jasmani yang memerlukan bimbingan dan pengarahan melalui proses pendidikan. ${ }^{79}$

\section{E. Hasil Penelitian}

Guru menjadi tumpuan harapan untuk mewujudkan agenda-agenda pendidikan nasional, peningkatan mutu yang relevan, pemerataan dan perluasan kesempatan peningkatan efisiensi dalam belajr. Dalam hal ini guru merupakan suatu pekerjaan profesional. Untuk dapat melaksanakan tugas tersebut dengan baik sehingga dapat dijadikan teladan oleh anak didik yaitu digugu ucapannya dan ditiru perbuatannya, baik yang berhubungan dengan aspek kognitif, afektif maupun psikomotorik.

Sebagai individu yang berkecimpung dalam dunia pendidikan, guru harus memiliki kepribadian yang mencerminkan seorang pendidik. Tuntutan akan kepribadian sebagai pendidik kadang-kadang di rasakan lebih berat di banding profesi lainya. Ungkapan yang sering di kemukakan adalah bahwa "guru bisa di gugu dan di tiru". Digugu maksudnya bahwa pesan-pesan yang di sampaikan guru bisa di percaya untuk di laksanakan dalam kehidupan sehari-hari dan pola hidupnya bisa di tiru atau di teladani. Guru sering di jadikan panutan oleh masyarakat dan lingkungan di mana ia bertempat tinggal, untuk itu seorang guru harus mampu memahami dan mengenal nilai-nilai yang berkembang di masyarakat dan yang dianut oleh masyarakat setempat. Secara nasional, nilai-nilai tersebut sudah di rumuskan, tetapi barang kali masih ada nilai yang belum terwadahi dan

\footnotetext{
${ }^{79}$ M. Arifin, Ilmu Pendidikan Islam, (Jakarta: Bumi Aksara, 2006), 103.
} 


\section{KONSEP KETELADANAN GURU DAN IMPLEMENTASINYA DALAM}

PERSPEKTIF PENDIDIKAN ISLAM

harus di kenal oleh guru, agar dapat melestarikanya, dan berniat untuk tidak berprilaku yang bertentangan dengan nilai tersebut. Jika ada nilai yang bertentangan dengan nilai yang dianutnya, maka dengan cara yang dengan cara yang tepat ia menyikapi hal tersebut, sehingga tidak terjadi benturan nilai antara guru dan masyarakat yang berakibat terganggunya prosese pendidikan bagi peserta didik. Untuk kepentingan tersebut, wawasan nasional mutlak diperlukan dalam pembelajaran.

\section{F. Kesimpulan dan saran}

Bahwa nilai moral yang terkandung dalam keteladanan dalam pendidikan terhadap tercapainya tujuan pendidikan secara maksimal maka saran yang dapat penulis sampaikan sebagai berikut: Digugu dan ditiru harus menjadi motivasi bagi para pendidik untuk menanamkan siakap keteladanan, baik keteladanan dari segi kognitif, psikomotor, maupun afektif. Sikap ini sangat penting di miliki oleh para pendidik untuk menghasilkan generasi yang cakap dan bermoral.

Seorang pendidik seyogyanyalah memahami tugasnya yang tidak hanya mentransfer ilmu pengetahuan semata tetapi lebih dari itu, menciptakan SDM yang mampu bertanggung jawab atas keilmuannya. Guru bukanlah tenaga super yang serba bisa. Tujuan pendidikan tidak akan tercapai secara maksimal tanpa adanya dukungan dari masyarakat dan pemerintah. Pemerintah harus memberikan sistem pendidikan yang kukuh sesuai dengan amanat tujuan pendidikan nasioanal, sementara masyarakat ikut mendukung segala kebijakan yang di tetapkan oleh lembaga pendidikan. 


\section{G. Daftar Pustaka}

Al Qur'an dan Terjemahannya, Departemen Agama RI, 2001. Bandung: Diponegoro Amirin, Tatang, 1995. Menyusun Rencana Penelitian, Cet. III, Jakarta: Raja Grafindo Persada

An-Nahlawi, Abdurahman, 2002. Pendidikan di Rumah Sekolah dan masyarakat, Jakarta: Gema Insani Press.

Azmi, Muhammad, 2006. Pembinaan Akhlak Anak, Jogjakarta: Blukar

Bakar, Hamdani Az Zaky, 2006. Konseling dan Psikoterapi Islam, Jogjakarta: Pustaka Pelajar Baru

Baraja, Abu Bakar, 2006. Mendidik Anak dengan Teladan, Jakarta: Studia Press

Baidan, Nasyiruddin, 2008. Metode Penafsiran Al Qur'an, Jogjakarta: Pustaka Pelajar

Buchori, Muchtar, 1944. Spektrum Problematika Pendidikan di Indonesia, Jogjakarta: Yiara Wacana

Daradjat, Zakiyah, 2004. Ilmu Pendidikan Islam, Jakarta: Bumi Aksara

Djamarah, Syaiful Bahri , 2000. Guru dan Anak dalam Interaksi Edukatif, Jakarta: Rineka Cipta

Engkoswara, 1984. Dasar-Dasar Metodologi Pengajaran, Jakarta: Bumi Aksara

Furchan, Arif, tth. Pengantar Penelitian dalam Pendidikan, Surabaya: Usaha Nasional Hadi, Sutrisno, 2004. Metodologi Research, Jil. I, Jogjakarta: Andi Offset

Hamalik, Oemar, 2007. Dasar-Dasar Pengembangan Kurikulum, Bandung: remaja Rosdakarya

Marimba, Ahmad D., 1980. Pengantar Filsafat Pendidikan Islam, Bandung Al-Ma'arif

Muhajir, Noeng, 1996. Metode Penelitian Kualitatif, Ed. III, cet. VII, Jogjakarta: Rake Sarasin

Nata, Abuddin, 2001. Paradigma Pendidikan Islam, Jakarta: Grasindo

Ramayulis, 2006. Ilmu Pendidikan Islam, Jakarta: Kalam Mulia

Sudirman, 2007. Interaksi dan Motivasi Belajar Mengajar, Jakarta: Raja Grafindo Persada

Samir, Mahmud, 2001. Guru Teladan di Bawah Bimbingan Allah, Bandung: remaja Rosda Karya 